\title{
Imagery and subjective categorization effects on long-term recognition and retrieval*
}

\author{
LOWELL D. GRONINGER \\ University of Maryland Baltimore County, Baltimore, Maryland 21228
}

\begin{abstract}
Twenty-five words that were either high or low in imagery ratings were used to study the effects of imagery and subjective catagorization instructions on recognition and retrieval after a 6-week interval. The results showed no significant effect for instructions on recognition memory, but there was a smaller loss of retrieval cues when imagery instructions were used in conjunction with words of high-imagery rating. High-imagery words also created superior free recall and recognition. The results were interpreted as showing the robustness of imagery coding on retrieval cues.
\end{abstract}

The memory process can be viewed as involving at least two partially independent systems. One system involves associating items with a context such that they can be later recognized in relation to that context. The other system involves the process of generating these items from cues, either specific, as in the case of paired associates, or nonspecific, as in the case of free recall. Although views of this type can be formalized (e.g., Anderson \& Bower, 1972), for the purposes of the present study it will suffice to note that measures of recognition memory reflect primarily the former system while measures involving recall given recognition reflect the latter.

Within this framework, the research on imagery using relational paradigms such as paired associates show that imagery facilitates the ability of an item to be generated, but does not at the same time facilitate the item's distinguishability as measured by recognition memory (Bower, 1970). However, the possibility exists that situational constraints in the typical paired-associate procedure, such as a limited presentation time per item, may mask the true nature of the imagery effects. Since time is an important factor in imagery with paired associates (Wood, 1967; Bugelski, Kidd, \& Segman, 1968), an unconstrained method of presentation would seem to be the best way to assure that all words would be coded under conditions that would optimize the effects of imagery. Thus, the present study employed an unconstrained learning period followed by a 6-week retention period to allow enough forgetting to show any relevant effects from the way in which words were coded.

The imagery conditions in the present study were compared to a subjective categorization technique similar to that used by Mandler (1967). It was anticipated that by varying words of high and low image-evoking power, and looking at the effects of instructions after a 6-week retention period, the study

\footnotetext{
*This paper is sponsored by Marilyn D. Wang, who takes full editorial responsibility for its contents.
}

would provide further information on the strength of various components of memory involved in imagery and verbal coding.

\section{METHOD}

\section{Experimental Design}

A factorial design was used with two levels of two factors. The factors were: (1) imagery rating, with words chosen to be either high or low on the imagery norms of Paivio, Yuille, and Madigan $(1968) ;(2)$ instructions, the instructions being either to learn the words ththrough imagery (method of loci) or by arranging the words in natural groups or categories. The Ss were students enrolled in the introductory psychology course.

\section{Procedure}

Fifty high-imagery and 50 low-imagery words were chosen in haphazard fashion from the norms of Paivio et al (1968). The only constraint in selection was an attempt to represent a broad range of words with different initial letters. The high-imagery words had a rating of not less than 6.4 on the 7-point scale used by Paivio et al (1968), while the low-imagery words had ratings of not more than 4 .

Within each 50-word group, six groups of 25 were selected at random and typed on $3 \times 5$ cards. For each deck, the 25 words not selected were used as distractor items for the recognition memory task.

Ss were given instructions by condition in groups of six or less, then sent to individual enclosed booths to perform the task. The Ss in the imagery conditions were instructed as follows: "This is an experiment in imagery. The first thing I would like you to do is to go into booths and learn 25 familiar locations in order and form a clear mental picture of each. For example, you may imagine yourself taking a walk through familiar buildings on campus, or taking a familiar drive, or perhaps thinking of rooms or places around your home. Try to form a vivid image of each location. When you have memorized the 25 locations and have a clear image of each, come to me and I'll give you further instructions. Any questions?"

(Later) "Here are 25 words. I would like you to learn the 25 words by picturing a visual representation of them in each location. For example, if the first word is 'beauty,' you might picture a beautiful flower or girl in the first location; if the word is 'lion,' try to form an image of a lion in the first location. Try to encompass the constructed image of the word with the image of the location. In other words, try to make a vivid compound image containing both the location and a representation of the word. When you are reasonably sure you can recall the 25 words, 
Table 1

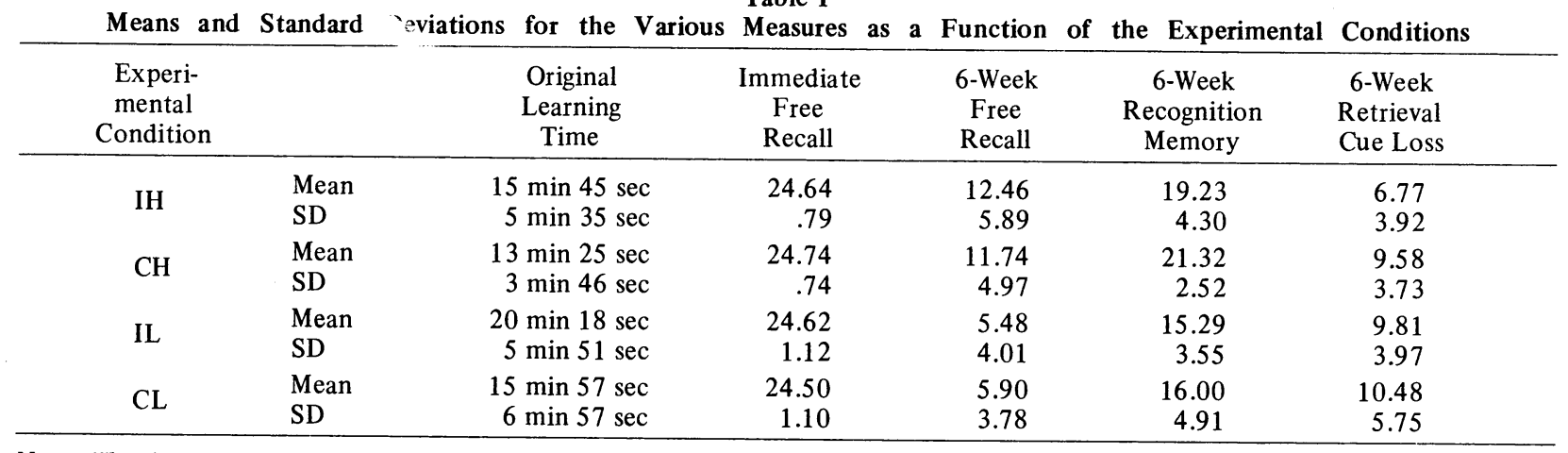

Note-The letters representing conditions stand for imagery, categorization, high, and low.

check yourself, then come to me, and I'll check your recall by having you write out the 25 words. I'll be timing you to see how long it takes. Any questions?" The group that had low-imagery words were also told that images might be difficult to form for some words, but to try anyway. The Ss receiving categorization instructions were told to take the deck and learn the words by laying the cards on the table and putting the words into groups of any size. They were also told that they would be timed and that when they were reasonably sure that they could write all of the words to come out of the booth and write them for the E.

Upon completion of the task, Ss were given questionnaires inquiring about their learning strategies and then dismissed. Six weeks later, the Ss were called for another experiment to be performed the following day. When they reported for the experiment they were asked to write all of the words that they could remember from the list that they had learned 6 weeks previously. Following this task, the Ss were given a sheet of paper with the 25 words randomly interspersed with 25 distractors of the same word type. The Ss were asked to place a number from 1 to 5 beside each word to indicate whether they thought the word was "old" or "new" and their confidence in that rating. The scale, written at the top of the page, was: " 1 " means very sure the word is a word from the previous list ("old" word); "2" means fairly sure, "old" word; "3" means just guessing; "4" means fairly sure the word was not on the previous list ("new" word); "5" means very sure, "new" word. In all recall and recognition tasks, Ss were given as much time as they wished. After the Ss had completed the recognition memory task, they were given questionnaires inquiring about if and how many times they might have rehearsed the list during the 6-week interval.

Ss' data were not used if: (1) they could not recall at least 23 items during Session 1, (2) their questionnaires in Session 1 showed that they had not adopted a learning strategy consistent with the instructions that they had been given, or (3) they reported rehearsing the words at any time during the 6-week retention interval other than on the day of Session 1 or on the day preceding Session 2. The attrition with these criterion was $12,10,7,10$ for the imagery-high, imagery-low, catagorization-high, catagorization-low conditions, respectively. The remaining $\mathrm{N}$ on which the analysis was based was $22,21,19$, 20 for the respective conditions. Although the substantial loss of $\mathrm{N}$ with the rejection criteria is undesirable in terms of random sampling, the remaining $\mathrm{N}$ was large enough to show any substantive effects that might exist, and the elimination of the data with extraneous effects reduces the probability of confounded results.

\section{RESULTS}

Table 1 shows the basic data of the experiment. All comparisons are shown although the major aspects of interest are: (1) recognition memory, reflecting trace discriminability after a 6-week interval, (2) recognition memory minus free recall, reflecting the extent to which retrieval cues were lost. A two factor analysis of variance showed that both instructions and word type were significant for the learning times of the 25 words, $F(1,79)=6.92, p<.01, F(1,78)=7.82, p<.007$, with faster learning occurring with categorization instructions as opposed to imagery instructions, and with high-imagery words as opposed to low-imagery words. The interaction was not significant. Since there were significant differences in the learning times between conditions, correlation coefficients were computed between learning times and subsequent retrieval measures within each condition. All correlations were not significantly different from zero except for a correlation of -.42 between learning time and free recall in the imagery-high group. It can therefore be concluded that the different learning times did not bias the subsequent retrieval measures except for the imagery-high group, and the effect there in contrast with the categorization-high group would be to make the conclusions more conservative.

The means representing immediate recall of the words were so close that no adjustment was made for these differences on later recall. The only significant effect at 6-week free recall was that many more high-imagery words were recalled than low-imagery words, $F(1,79)=$ $37.47, \mathrm{p}<.001$.

In utilizing the recognition memory data, a check was made on the use of the confidence scale by Ss. Table 2 shows that the confidence scale separated the words on the original list ("old") words from the distractor ("new") words in a fashion consistent with the intent of the scale. The hit rates and false alarm rates by condition are given in Table 3 and show consistency, particularly within type of word. In assessing the recognition memory data in terms of number correct, two analyses were made based on stringency of criterion. For the "strict" criterion only " $1 \mathrm{s"} \mathrm{data} \mathrm{were} \mathrm{used} \mathrm{while} \mathrm{the}$ " $1 \mathrm{~s}$ " and " $2 \mathrm{~s}$ " data were combined for the "lenient" criterion. Since no substantial difference in the effects of 
lable 2

Percent of "Old" Words at 6-Week Recognition Within the Confidence Ratings

\begin{tabular}{cccccc}
\hline \multirow{2}{*}{$\begin{array}{c}\text { Experi- } \\
\text { mental } \\
\text { Condition }\end{array}$} & \multicolumn{5}{c}{ Confidence Ratings } \\
\cline { 2 - 6 } & 1 & 2 & 3 & 4 & 5 \\
\hline IH & .94 & .65 & .42 & .18 & .07 \\
CH & .96 & .72 & .38 & .12 & .04 \\
IL & .88 & .60 & .37 & .18 & .16 \\
CL & .88 & .50 & .42 & .17 & .10 \\
\hline
\end{tabular}

Table 3

Hit and False Alarm Rates at 6-Week Recognition for the Experimental Conditions Within the 1 and 2 Confidence Ratings

\begin{tabular}{|c|c|c|c|c|}
\hline \multirow{3}{*}{$\begin{array}{l}\text { Experi- } \\
\text { mental } \\
\text { Condition }\end{array}$} & \multicolumn{4}{|c|}{ Confidence Ratings } \\
\hline & \multicolumn{2}{|c|}{1} & \multicolumn{2}{|c|}{2} \\
\hline & Hit & FA & Hit & FA \\
\hline IH & .93 & .07 & .63 & .17 \\
\hline $\mathrm{CH}$ & .97 & .05 & .82 & .18 \\
\hline IL & .87 & .16 & .72 & .28 \\
\hline $\mathrm{CL}$ & .92 & .14 & .59 & .34 \\
\hline
\end{tabular}

the two analyses occurred, Table 1 shows only the data for hits minus false alarms for the combination of " $1 \mathrm{~s}$ " and " 2 s." The only significant recognition memory effect in a two factor analysis of variance was for word type, high-imagery words being recognized more frequently than low-imagery words, $\mathrm{F}(1,79)=28.05$, $\mathrm{p}<.001$. In determining retrieval cue loss, it was decided to subtract free recall from recognition rather than take a contingent probability measure for two reasons. Firstly, the subtraction method removes the problem of deciding if equal percentages based on different base scores reflect the same degree of retention. Secondly, the variability within scores is less with the subtraction procedure.

The analysis on the durability of retrieval cues showed that retrieval was significantly better for high-imagery words than low-imagery words, $F(1,79)=4.25, p<.05$. The comparisons involving loss of retrieval cues showed a smaller loss under imagery instructions than for instructions to use subjective catagorization, although the effect was marginal, $F(1,79)=3.40, p=.07$. The interaction was not significant at the .05 level. The two cells involving words of high-imagery ratings are of special interest in relation to retrieval cue loss since it is with these words that the effects of imagery instructions should be most pronounced. A t test on these two cells showed significantly less retrieval cue loss with imagery instructions, $\mathrm{t}=2.46, \mathrm{p}<.05$.

\section{DISCUSSION}

The results of this study in terms of recognition memory are essentially in agreement with Bower's (1970) findings concerning imagery as a relational organizer using paired associates. Bower found that imagery instructions did not make the stimulus members of word pairs more discriminable as measured by a recognition memory task but did increase the number of words that were generated. The present study also found no significant differences in recognition memory scores for the types of instruction, but did find that imagery instructions produced less retrieval cue loss, compared to other instructions when words rated high on an imagery scale were used. If a "strength" concept is adopted in terms of retrieval cues stored in input, the present study implies that imagery coding, in conjunction with words easy to image, is of sufficient strength to maintain superior retrieval cues over a period of weeks. Thus, imagery findings using paired-associate learning are not unique to that method or to the relatively short retention times involved in that method. Instead, the effects of this study which are similar to those of Bower (1970), who used a much different paradigm, indicate that imagery effects on retrieval cues are robust within the memory system.

Another important finding in the present study was that the strongest effect in the experiment came from word type, words high in imagery rating creating consistently higher free recall and recognition memory scores. However, in terms of retrieval cue loss, word type was only significant in conjunction with imagery instructions. Thus, while word type seems to be the dominant factor in memory within the present study, imagery instructions make a unique contribution in terms of retrieval cues.

\section{REFERENCES}

Anderson, J. R., \& Bower, G. H. Recognition and retrieval processes in free recall. Psychological Review, 1972, 79 , 79-123.

Bower, G. H. Imagery as a relational organizer in associative learning. Journal of Verbal Learning \& Verbal Behavior, 1970 $9,529-533$.

Bugelski, B. R., Kidd, E., \& Segman, J. Image as a mediator in one-trial paired-associate learning. Journal of Experimental Psychology, 1968, 76, 69-73.

Mandler, G. Organization and memory. In K. W. Spence and J. T. Spence (Eds.), The psychology of learning and motivation. Vol. 1. New York: Academic Press, 1967.

Paivio, A., Yuille, S. C., \& Madigan, S. Concreteness, imagery and meaningfulness values for 925 nouns. Journal of Experimental Psychology, Monograph Supplement, 1968, 76(1, Pt. 2).

Wood, G. Mnemonic systems in recall. Journal of Educational Psychology Monographs, 1967, 58(6, Pt. 2).

(Received for publication January 24, 1973.) 